\title{
A NEW APPLICATION OF PSYCHOLOGY TO INDUSTRY
}

\author{
By Henry C. LINK, Ph D.
}

The following experiment, conducted in a sporting goods factory where the use of psychological tests for employment purposes has been extensively developed, indicates an entrrely new way in which tests can be applied.

An inspection shop, where some 80 girls were employed as bullet inspectors, was having difficulty with the current piecework rate of pay. The foreman of the shop claimed that the rate was too low and that he was finding it impossible to retain his inspectors because of their dissatisfaction with their earnings. However, the time-study group whose business it was to set piece-work rates, asserted that the rate was a just one. Moreover, they showed that it was the highest rate which had ever been paid for that kind of work. An investigation proved that both claims were apparently well founded, and yet the investigation contributed nothing in the way of an intelligent solution of the problem.

For the benefit of those who do not understand the piecework rate or how it is set it will be necessary to give a brief description. The piece-work rate is a rate of remuneration which is governed by the quantity of work an individual performs. It is a rate which enables each worker to profit directly according to his capability This rate, however, must first of all be determined, and this process requires a special study of the work to be done and of the comparative capabilities of those selected to do it. The men who make this study and who then set the rate are usually called time-study men from the fact that their study consists largely of timing, by means of a stop watch, the elements of the work or operation for which the rate is to be set

For example, in setting the rate for bullet inspectors, a time-study man first analyzes the operation into its elements, perhaps as follows:

1. Picking up a handful of bullets.

2. Inspecting bullet points.

3 . Reversing bullets and inspecting bases.

4. Rolling bullets out of left hand into right and inspecting lateral surface. 
This constitutes a complete "cycle" in the operation of bullet inspecting. By means of a stop watch, the time-study man proceeds to time each element of this cycle, timing as many cycles as he may think necessary. He may time the work of an inspector for one or two hours or even half a day, depending on the difficulty or importance of the rate to be set. In this way he obtains both the total time it takes the inspector to perform a certain amount of work, and also the various times required by each element in the operation. He then repeats his observations on the work of several more inspectors. On the basis of the results which he obtains from these time studies, the time-study man computes what he regards a fair average rate of production, or the amount of work which a girl of average ability may fairly be expected to do. On this basis, after certain allowances of time for fatigue, personal necessities, and other possible interruptions have been made, the rate is set.

Rate setting by means of a time study is, therefore, in one sense, a psychological experiment, for it attempts to make an accurate record of a series of well-defined reaction times, and on this basis to compute the time for a series of typical reactions. However, it can readily be seen from the above description of the time-study process that the rate resulting from such a study depends almost entirely upon the subjects selected for observation. If the subjects selected are representative of the group to which they belong, the study is likely to have a valuable result. If the subjects selected are not representativeand this is frequently the case-the resulting rate will be too high or too low. For instance, a piece rate for fifty or more workers is often based upon a study of only two or three subjects. No sound statistical procedure is applied to control the great possibilities of error which may here arise. Moreover, there is an equal lack of statistical soundness in the method by which the subjects who serve as the basis of the time-study are chosen It is quite customary for the timestudy man to go to the foreman and ask him to pick out two or three representative girls, one fast worker, a slow worker, and an average worker. The foreman, who most frequently has his own axe to grind, naturally picks out those workers who will be most likely to give the result he himself desires.

In the instance mentioned at the opening of this paper, the rate set had proved unsatisfactory However, it was impossible to determine whether the rate had been set too low; or whether the girls who were doing the work were of unusually 
low ability; or in fact, where the real difficulty lay. The experiment described here was conducted in an attempt to cast further light on this problem.

The eighty bullet inspectors were all employed at the same kind of work. The first object of the experiment was to discover how these girls compared with other inspectors who were doing similar work in other shops of the same company. The comparison was to be based upon a set of tests which had already been given to large numbers of inspectors in other shops. Two tests were given to each girl, the WoodworthWells cancellation test and the Woodworth-Wells number group checking tests. These two tests had been found very significant in previous experiments with inspectors, having shown consistently high correlations. ${ }^{1}$ The two tests were given to each girl at her work bench and occupied about ten minutes for each subject. Forty-two of the eighty inspectors, selected at random, were tested in this way. It was taken for granted that the other thirty-eight subjects would not materially alter the averages obtained. The average performance of the forty-two bullet inspectors in these two tests was then compared with the average performance in these tests found for other groups of inspectors. The figures on which this comparison was based are given below, the results of the present experiment being put last.

$\begin{array}{ccccc}\begin{array}{c}\text { Inspecting } \\ \text { Shops }\end{array} & \begin{array}{c}\text { Tests Given } \\ \text { in 1917 }\end{array} & \begin{array}{c}\text { No. of Girls } \\ \text { Tested }\end{array} & \begin{array}{c}\text { Av. Perf. in } \\ \text { no. Group } \\ \text { Test }\end{array} & \begin{array}{c}\text { Av. Perf. in } \\ \text { Canc. Test }{ }^{2}\end{array} \\ \text { A } & \text { April } & 50 & 161 & 122 \\ \text { A1 } & \text { Nov. } & 66 & 174 & 136 \\ \text { B } & \text { June } & 12 & 175 & 122 \\ \text { C } & \text { June } & 22 & 183 & 160 \\ \text { D } & \text { May } & 30 & 187 & 136 \\ \text { E } & \text { Dec. } & 42 & 191 & 139\end{array}$

The comparison showed that the bullet inspectors were poorer than any other group of inspectors in the number group checking test (the test which had shown the most significant correlations in previous experiments), and poorer than any other group but one in the number cancellation test (the next most significant test). It was inferred from this that the dissatisfaction of the bullet inspectors was probably due to this comparative inferiority rather than to the lowness of the rate. However, the experiment did not conclude with this inference.

1 The details of these experiments are described in the writer's book on Employment Psychology.

2 Corrected time in seconds. 
After a girl had been tested and the observer had picked up his materials, he would ask in a casual way, "How are you making out?" Of the number of girls asked, sixteen expressed themselves as not doing well or as being often discouraged, and only five expressed satisfaction. The rest were incoherent or inconclusive This pointed to a more or less general dissatisfaction among the girls. It was obviously unfair to attribute all of this dissatisfaction to the existing rate. Furtherobservation revealed the following contributıng causes:

First, when a box of improperly inspected bullets was found, it was returned to the inspector for reinspection and had to be inspected again without pay This was customary and expected. However, in the Bullet Inspecting Shop the boxes to be re-inspected were usually held back until 5 o'clock in the evening and only then returned to the careless inspector. In this way a girl, laboring under the impression that she was about to earn a good day's pay, might suddenly find herself, near the end of the day, confronted with a box or two of bullets which would have to be done over without pay. This spoiled her day and was quite likely to make her discouraged. It was therefore recommended that all work to be re-inspected should be returned to the inspector as soon as possible after being discovered, in order that the punishment might be as closely associated with the mistake as possible and in order to avoid ending the day with a discouraging incident. This recommendation was followed. In addition it was ordered that no bad work should be returned for reinspection after 3:00 P. M.

Secondly, it was observed that the bullets to be inspected were given to the inspectors in boxes holding as much as eighty pounds or more It took about two hours to inspect one box, and five or six boxes constituted a day's work When the check inspector found a few bad bullets in a box that had been inspected, the whole box must be returned for reinspection This meant that about one-fifth of the inspector's whole day's work had been in vain and consequently she was likely to become still more discouraged. It was therefore recommended that the quantity of bullets in a box should be cut in half, and forty instead of eighty pounds given to a girl at one time. In this way, ten or twelve boxes would constitute a day's work; and if a girl worked carelessly at one time, so that a box of bullets was returned to her for reinspection, she would suffer only half as much as before At the same time she would receive a warning which would give her an opportunity to avoid repeating her mistakes 
Thirdly, it was observed that the inspection required unusually fine eyesight Investigation showed that $19 \%$ of all the work inspected was returned for remspection This was a factor to be taken into consideration in making a final adjustment of the rate.

Fourthly, the observer discovered that a practical embargo had been placed on the amount of work the inspectors were allowed to do. The limit set was seven hundred pounds. This limit was set on the supposition that a girl could not inspect more than seven hundred pounds and do them well. Aside from the fact that this ruling was in total contraversion of the prece-work principle, it also served as a discouragement to the very fast inspectors, who chafed under such a limitation This limit was removed

These observations, while not strictly psychological-that is, in the technical sense-nevertheless were directly traceable to the psychological attitude. Moreover, they were a distinct contribution to the solution of the problem.

If the tests had not been made, it might have been arbitrarily decided that the rate of pay was high enough, in which case the work of the shop might have suffered a decided detriment Or it might have been arbitrarily decided that the rate was too low, in which case the production of the shop might not have been increased and the real root of the difficulty would have been 1gnored. Either course would have proved unsatisfactory to one group of claimants or the other. The results of the experiment gave a concrete and well-founded reason for maintaining the existing rate, at least for the time being or until the effects of the supplementary changes recommended could be observed As a matter of fact, it was unnecessary to change the rate, in spite of the fact that results in the tests indicated that the bullet inspectors were not as capable as the other inspectors

This experıment suggests certain broad potentialities of industrial psychology. The problem of setting rates is a universal industrial problem, and it is one of the most delicate and trouble-making questions with which industries have to deal The time-study method, which is aimed chiefly at increasing production, can be distinctly supplemented by the psychological method. There is no antrthesis or contradiction between the two methods for, as the above experiment clearly shows, a psychological study as well as a time study, may contribute materially to production. Moreover, in contrast with the usual procedure, an increase in satisfaction and in production may sometimes be effected without an increase in the rate of pay. 